\title{
1 Marine snow as a habitat for microbial mercury methylators in the Baltic Sea
}

2

3 Eric Capo ${ }^{1}$, Andrea Garcia Bravo ${ }^{2}$, Anne L. Soerensen ${ }^{3}$, Stefan Bertilsson ${ }^{4}$, Jarone Pinhassi ${ }^{5}$,

4 Caiyan Feng ${ }^{1}$, Anders F. Andersson ${ }^{6}$, Moritz Buck ${ }^{\text {LA,4 }}$, Erik Björn ${ }^{\text {LA, } 1}$

$6 \quad{ }^{1}$ Department of Chemistry, Umeå University, Umeå, Sweden

$7 \quad{ }^{2}$ Department of Marine Biology and Oceanography, Institute of Marine Sciences, Spanish National

8 Research Council (CSIC), Barcelona, Spain

$9{ }^{3}$ Department of Environmental Research and Monitoring, Swedish Museum of Natural History,

10 Stockholm, Sweden

$11{ }^{4}$ Department of Aquatic Sciences and Assessment, SLU Uppsala, Sweden

$12{ }^{5}$ Centre for Ecology and Evolution in Microbial Model Systems - EEMiS, Linnaeus University,

13 Kalmar, Sweden

$14{ }^{6}$ Department of Gene Technology, KTH Royal Institute of Technology, Science for Life Laboratory,

15 Solna, Sweden

$16{ }^{\text {LA }}$ Moritz Buck and Erik Björn are joint last authors of this work

18 Corresponding author: Eric Capo; eric.capo@ hotmail.fr

19 Running title: Mercury methylators in marine snow from Baltic Sea 


\section{Abstract}

23 Methylmercury (MeHg), a neurotoxic compound biomagnifying in aquatic food webs, can be a

24 threat to human health via fish consumption. However, the composition and distribution of the

25 microbial communities mediating the methylation of mercury $(\mathrm{Hg})$ to $\mathrm{MeHg}$ in marine systems

26 remain largely unknown. In order to fill this gap of knowledge, we used the Baltic Sea Reference

27 Metagenome (BARM) dataset to study the distribution of the genes involved in Hg methylation (the

$28 h g c A B$ gene cluster). We determined the relative abundance of the $h g c A B$ genes and their

29 taxonomic identity in 81 brackish metagenomes that cover spatial, seasonal and redox variability in

30 the Baltic Sea water. The $\operatorname{hg} A B$ genes were predominantly detected in anoxic water, but some

31 hgcAB genes were also detected in hypoxic and normoxic waters. Higher relative quantities of

$32 h g c A B$ genes were found in metagenomes from marine snow compared to free-living communities

33 in anoxic water, suggesting that marine snow are hotspot habitats for $\mathrm{Hg}$ methylators in oxygen-

34 depleted seawater. Phylogenetic analysis identified well-characterized $\mathrm{Hg}$ methylators such as

35 Deltaproteobacteria in oxygen-depleted water, but also uncovered $\mathrm{Hg}$ methylators within the

36 Spirochaetes and Lentisphaerae phyla. Altogether, our work unveils the diversity of the

37 microorganisms mediating $\mathrm{MeHg}$ production in the Baltic Sea and pinpoint the ecological niches of

38 these microorganisms within the marine water column.

\section{Introduction}

42 Methylmercury $(\mathrm{MeHg}$ ) is a neurotoxic compound that accumulates in aquatic food webs and may

43 be a threat to human health related to fish consumption (Mason et al., 2012). Methylation of

44 inorganic mercury $(\mathrm{Hg})$ to $\mathrm{MeHg}$ is predominantly a biological process driven by anaerobic bacteria

45 and archaea carrying the $h g c A$ and $h g c B$ genes (Parks et al., 2013) and takes place in various

46 oxygen-deficient environments (e.g. sediment, water, soil). $\mathrm{Hg}$ methylation appears to be controlled

47 by the activity of $\mathrm{Hg}$-methylating microbes, the composition and activity of microbial communities 
48 (that indirectly modulate $\mathrm{Hg}$ methylation), and $\mathrm{Hg}$ bioavailability (Bravo and Cosio, 2019). It is

49 broadly established that the capacity for $\mathrm{Hg}$-methylation is limited to specific microbial lineages,

50 with the most commonly reported groups found in the Deltaproteobacteria and Methanomicrobiales

51 (Gilmour et al., 2013; Podar et al., 2015; Bravo et al., 2018; Yu et al., 2018). However, a recent

52 work has unravelled a higher phylogenetic diversity of microbes carrying the $h g c A B$ genes than

53 previously expected (McDaniel et al., 2020) and this calls for novel analyses of microbial $\mathrm{Hg}$ -

54 methylation in aquatic environments.

56 Recent advances in metagenomics have yielded new insights into the microbial taxonomic and

57 functional diversity in various aquatic ecosystems (e.g., Mehrshad et al., 2016; Haro-Moreno et al.,

58 2018; Nowinski et al., 2019). The approach has for example been applied to broadly assess the

59 presence and diversity of genes central to biological $\mathrm{Hg}$ cycling in marine systems (Podar et al.,

60 2015; Gionfriddo et al., 2016; Bowman et al., 2019; Villar et al., 2020). Podar et al. (2015) only

61 detected $h g c A B$ genes in a few metagenomes from marine pelagic waters (seven out of 138

62 metagenomes) but highlighted that limited sequencing depths of these metagenomes could have

63 hampered detection. A more recent study did not detect $h g c A$ genes in waters from the Arctic and

64 equatorial Pacific Oceans (Bowman et al., 2019). Interestingly, the presence of $h g c A B$-like genes

65 was reported in normoxic water from open ocean and sea ice in Antarctica, with a fraction of those

66 genes being associated to microaerophilic nitrite oxidizing bacteria (Gionfriddo et al., 2016; Villar

67 et al., 2020). Further, Blum et al. (2013) demonstrated that between 20 and $40 \%$ of $\mathrm{MeHg}$

68 measured in surface mixed layer of the North Pacific Ocean originated from internal production in

69 the surface water.

71 Marine snow (organic-rich particulate matter and aggregates) is hypothesized to provide both

72 substrates for heterotrophic microbes (Azam and Long, 2001; Azam and Malfatti, 2007) and

73 various anaerobic microenvironments (Alldredge and Silver, 1988; Bianchi et al., 2018) that could 
74 potentially favor $\mathrm{Hg}$ methylation, via e.g. microbial sulfate-reduction. Based on this, several studies

75 proposed (Lehnherr et al., 2001, Monperrus et al., 2007, Cossa et al., 2009, Sunderland et al., 2009,

76 Schartup et al., 2015) or demonstrated (Oritz et al., 2015; Gascón Diez et al., 2016) Hg methylation

77 in settling particles. For the Baltic Sea it has been proposed that $\mathrm{Hg}$ methylation in normoxic water

78 can be associated with phytoplankton blooms via production of increased levels of phytoplankton

79 derived OM (marine snow) sinking through the water column (Soerensen et al., 2016) providing

80 suitable anoxic niches for $\mathrm{Hg}$ methylators. However, as far as we know there are no studies on

81 microbial communities in relation to this phenomenon in the Baltic Sea or elsewhere. In addition to

82 the oxygen-deficient microzones in marine snow, Oceans and coastal seas, such as the West Coast

83 of South America, the Arabian Sea and the Baltic Sea, have experienced increased deoxygenation

84 since at least the middle of the $20^{\text {th }}$ century (Breitburg et al., 2018). This phenomenon can be

85 caused by (i) warming that decreases the solubility of oxygen in the ocean and (ii) nutrient

86 enrichment of coastal water causing an increase of algal biomass and subsequent decomposition of

87 sinking organic matter by microbes consuming the oxygen (Breitburg et al., 2018). Such oxygen

88 deficient waters potentially offer ecological niches suitable for Hg-methylating microorganisms.

89 Overall there are still important knowledge gaps concerning the process of $\mathrm{Hg}$ methylation in

90 aquatic systems, in particular regarding variable redox conditions.

92 The Baltic Sea is an ecosystem that has experienced large increases in nutrient loads and oxygen

93 consumptions over the last century, resulting in extensive coastal and offshore zones with

94 permanent hypoxic and anoxic water below the oxygenated surface water (Conley et al., 2011;

95 Carstensen et al., 2014). As such, the Baltic Sea represents a model for the expansion of coastal

96 ecosystems influenced by anoxia. Elevated $\mathrm{MeHg}$ concentrations in the Baltic Sea have been

97 observed in anoxic water (> $1000 \mathrm{fM}$ ) compared to hypoxic and normoxic water (Kuss et al., 2017;

98 Soerensen et al., 2018). Soerensen et al. (2018) demonstrated that this was caused by increased

99 rates of $\mathrm{Hg}$ methylation in the oxygen deficient water zones. They hypothesized that this process is 
100 predominantly driven by microbial sulfate-reduction because of the relatively high concentrations in

101 dissolved sulfide in the anoxic water (up to $\sim 60 \mu \mathrm{M} \mathrm{S}^{-\mathrm{II}}$ ). Although the concentrations of $\mathrm{MeHg}$ in

102 normoxic water were generally low (13-80 fM), concentrations were higher than what could be

103 explained by MeHg input form external sources only, and the authors inferred in situ formation of

$104 \mathrm{MeHg}$ at a low rate also in normoxic water zones in the Baltic Sea (Soerensen et al., 2016, 2018).

105 The presence and distribution of microorganisms carrying the $h g c A B$ genes, including taxa known

106 to reduce sulfate, could unequivocally confirm the potential for in situ $\mathrm{MeHg}$ formation the Baltic

107 Sea.

108

109 In this study, we assessed the spatial and seasonal variability of the $h g c A B$ in the Baltic Sea,

110 including water column profiles, allowing us to investigate for the first time the presence and

111 variation of $\mathrm{Hg}$-methylating microbes across redoxclines in the Baltic Sea. We revealed the

112 presence and relative abundance of $\mathrm{Hg}$ methylators in both hypoxic and anoxic water masses of the

113 Baltic Sea while $h g c A B$ genes were present in very low abundance or not at all detected in

114 normoxic waters. In addition, we found a higher proportion of $h g c A B$ DNA sequences in

115 metagenomes obtained from $3.0 \mu \mathrm{m}$ filters compared to $0.2 \mu \mathrm{m}$ filters, suggesting marine snow as

116 an important habitat for $\mathrm{Hg}$ methylators. Our work provides new information on $\mathrm{Hg}$-methylating

117 microorganisms in coastal seas impacted by oxygen deficiency.

\section{Material and Methods}

120 The Baltic Sea Reference Metagenome (BARM) data (Alneberg et al., 2018) used in our study is

121 composed of 81 metagenomes combined from three datasets spanning 13 locations (Figure 1) and

122 selected to cover natural variation in geography, depth and seasons of Baltic Sea waters. A

123 summary on sampling and filtration of water samples for each of the datasets is provided in Table 1.

124 We classified the water samples into three categories based on the measured $\mathrm{O}_{2}$ concentrations: (i) 
125 normoxic water with $\mathrm{O}_{2}$ concentrations exceeding or equal to $2 \mathrm{~mL} \mathrm{O}_{2} \cdot \mathrm{L}^{-1}$ (ii) hypoxic water with

126 detectable $\mathrm{O}_{2}$ concentrations lower than $2 \mathrm{~mL} \mathrm{O}_{2} \cdot \mathrm{L}^{-1}$ and (iii) anoxic water with no detectable $\mathrm{O}_{2}$.

127 Methods for DNA extractions, library preparations and sequencing as well as the initial processing

128 of metagenomics data is described in greater details in Alneberg et al. (2018). Briefly, preprocessed

129 reads were co-assembled using Megahit (version 1.0.2, Li et al 2015). Functional and taxonomic

130 annotation was performed for the 6.8 million genes found on the 2.4 million contigs $>1$ kilobase. In

131 order to detect $h g c A B$ homologs genes, we first analyzed the 6.8 million predicted genes with the

132 function hmmsearch from the hmmer software (3.2.1 version, Finn et al., 2011) with the use of the

133 HMM profiles of $h g c A B$ protein sequences from Podar et al (2015) as a reference database

134 (Supplementary Text S1). We considered genes with E-values $\leq 10^{-3}$ as significant hits resulting in

135 a total of 3,215 genes. Only a fraction of these 3,215 genes correspond to $h g c A$ and $h g c B$ genes and

136 we therefore performed a manual check of their protein sequences using the knowledge from the

137 seminal paper of Parks et al. (2013) that described unique motifs in $h g c A(\mathrm{NVWCA}(\mathrm{A} / \mathrm{G} / \mathrm{S}) \mathrm{GK})$

138 and $h g c B$ protein sequences $(\mathrm{C}(\mathrm{M} / \mathrm{I}) \mathrm{EC}(\mathrm{G} / \mathrm{S})(\mathrm{A} / \mathrm{G}) \mathrm{C})$. For phylogenetic analysis, we used the

139 protein sequences of the $650 \mathrm{hgcAB}$ gene clusters identified as putative $\mathrm{Hg}$ methylators by

140 McDaniel et al. (2020). These 650 hgcAB gene clusters were obtained from the analysis of publicly

141 available isolate genomes and metagenome-assembled genomes (Supplementary Text S2, McDaniel

142 et al., 2020). For each phylogenetic analysis, protein sequences were aligned using MUSCLE

143 (cluster method UPGMA) in the software MEGAX (Kumar et al., 2018) and approximate

144 maximum likelihood (ML) trees were constructed using FastTree (Price et al., 2009). The trees

145 were visualized using iTOL (Letunic and Bork, 2019) and clades were collapsed by the dominant,

146 monophyletic phyla when possible for visualization ease.

\section{Results}


151 The total DNA sequence counts (number of reads) in the 81 Baltic Sea metagenomes ranged from

1521.6 to and 37 million reads (mean 12.9, sd: 9.7). Among the total of 6.8 million protein-coding

153 genes predicted from the co-assembly, $22 \mathrm{hgcA}$-like and $12 \mathrm{hgcB}$-like genes were detected. In some

154 cases, $h g c A$ and $h g c B$ genes were found side-by-side on the same contig. Overall, we detected: (i)

155 nine $h g c A B$-like gene clusters, (ii) $13 h g c A$-like genes, and (iii) three $h g c B$-like genes (Figure 2,

156 Supplementary Text S3). The resulting 25 gene clusters or single genes were named as displayed in

157 Figure 2. The thirteen $h g c A$-like genes found without a coupled $h g c B$ gene were always found at an

158 extremity of the respective contig, possibly explaining why no $h g c B$ genes were detected alongside.

159 In contrast, the three $h g c B$-like genes found alone on their respective contig were consistently found

160 in the central portions of the contigs, with no downstream or upstream protein motifs from $h g c A$

161 genes. Most of the $h g c A$ and $h g c B$ genes had the most common protein motifs, NVWCAAGK and

162 CMECGAC, respectively, as described by Parks et al. (2013). Two gene clusters contained both the

163 "NVWCASGK" and "CIECGAC" motifs (BARM-01 \& -09) while BARM-07 was the only gene

164 cluster with the NVWCAAGK and CIECGAC combination (Figure 2).

\section{Taxonomic identifications of $\mathrm{hgcAB}$-like genes found in the Baltic Sea}

167 In order to taxonomically identify each $\mathrm{Hg}$ methylation gene detected in the BARM dataset, we 168 constructed phylogenetic trees using the 650 hgcAB gene clusters generated by McDaniel et al.

169 (2020). For the nine $h g c A B$-like gene clusters concatenated, we performed a phylogenetic analysis

170 with the 650 hgcAB gene clusters (Figure 3, Supplementary File S1). For the 13 hgcA and three

$171 h_{g c B}$ genes detected alone in their respective contig, two additional phylogenetic trees were

172 performed using the $650 \mathrm{hgcA}$ and $650 \mathrm{hgcB}$ genes, respectively (Supplementary File S2 and S3).

173 The phylogenetic analysis revealed the presence of several $h g c$ genes (referring hereafter either to $174 h g c A B$ gene clusters, $h g c A$ genes or $h g c B$ genes) affiliated with the order Desulfobacterales 175 (Deltaproteobacteria, class Desulfobacterota in GTDB classification): a member of the family 176 Desulfobulbaceae (BARM-15 \& -17), a Desulfobacula sp. (BARM-04 \& -08), and a 
177 Desulforhopalus sp. (BARM-11) (Figure 3). In addition, the hgc genes BARM-02, -06 \& -10 were

178 associated with members of the orders Desulfatiglanales (naphS2 family) and Desulfarculales

179 (Desulfarculaceae family) and Syntrophales. The hgc genes BARM-01, -07, -09 \& -21 clustered

180 together and were closely related to genes detected in various microbial phyla, with the closest

181 related $h g c$ genes detected in the genomes of two Spirochaetes from the family Treponemataceae.

182 Three hgc genes (BARM-05, -19 \& -22) were associated with members of the Lentisphaerae

183 phylum, which is part of the widespread PVC superphylum (i.e. including Planctomycetes,

184 Verrucomicrobia, Chlamydiae and Lentisphaerae). In addition, some BARM hgc genes were

185 closely related to Firmicutes (Clostridia, BARM-14) and a group of $h g c$ genes from Euryarchaea

186 and Chloroflexi clustered together (BARM-18). Finally, seven BARM hgc genes were associated

187 with clades including various microbial lineages and are thus classified here as unidentified

188 (BARM-03, -12, -13, -16, -20, -23 \& -24).

\section{Relative abundance of $h g c A B$ genes in the Baltic Sea water column}

191 The summed relative abundance of $h g c A$ and $h g c B$-like genes in the Baltic Sea water column (i.e.

192 the number of reads for the $h g c A B$-like genes per total annotated reads per sample, expressed as \%)

193 ranged from undetected to $6.7 \times 10^{-3} \%$ (mean: $0.3 \times 10^{-3}$, sd: $1.2 \times 10^{-3}$ ) (Table 2, Figure 4). The

194 highest relative abundance of $h g c A B$-like genes was found in the hypoxic water from $76.5 \mathrm{~m}$ depth

195 at station S7 with $6.7 \times 10^{-3} \%$ (Figure 4). Elevated abundance of $h g c A B$-like genes was also found

196 in hypoxic and anoxic water from the TF0271/AT3 station with the highest values at a water depth

197 of $200 \mathrm{~m}$ with $6.5 \times 10^{-3} \%$. The proportion of $h g c A B$ genes detected in the other 10 locations was

198 relatively low with a maximum value of $0.2 \times 10^{-3} \%$ in the hypoxic layer $(87.5 \mathrm{~m})$ at station TF245

199 (Figure 4). At the LMO station, for which only normoxic water was sampled, the highest proportion

200 of $h g c A B$ genes found in the 37 samples was less than $0.01 \times 10^{-3} \%$ (sample LMO 120806 ,

201 Supplementary Table S1). We found that the most abundant $h g c A B$ genes in Baltic Sea anoxic

202 water belonged to members of Deltaprotebacteria, more specifically members of Desulfobulbaceae, 
Desulfarculaceae, Desulfobacula sp. and Syntrophales, and Spirochaetes from the Treponemataceae

204 family (Figure 4, Table S3).

\section{Differences in $h g c A B$ genes relative abundance with filter-size}

207 The quantity of $h g c A B$-like genes detected in metagenomes obtained from the Baltic Sea water

208 column differed systematically between filter size fractions (Figure 4). Metagenomes obtained from

209 the TF0271 station profile, and filtered onto $3.0 \mu \mathrm{m}$ filters (hereafter referred to as the " $3.0 \mu \mathrm{m}$

210 metagenomes"), had consistently higher proportions of $h g c A B$-like genes (up to $6.5 \times 10^{-3} \%$ ) than

211 metagenomes obtained from $0.2 \mu \mathrm{m}$ filters following pre-filtration with $3.0 \mu \mathrm{m}$ filters (hereafter

212 referred to as the "0.2-3.0 $\mu$ m metagenomes") (up to $1.5 \times 10^{-3} \%$ ) (Figure 4). This was especially

213 clear for the anoxic TF0271-Oct26 samples, where the relative abundance of $h g c A B$ genes was

214 three and 14 times higher in $3.0 \mu \mathrm{m}$ metagenomes compared to 0.2-3.0 $\mu \mathrm{m}$ metagenomes for

215 samples collected at 140 and $200 \mathrm{~m}$ depth, respectively (Figure 4, Supplementary Table S1). At

216 Boknis Eck, only a few samples were collected and the gene proportions were too low to properly

217 investigate differences between filtration methods. At TF0271, hgcAB genes from

218 Deltaproteobacteria were predominant for both 0.2-3.0 and 3.0 $\mu \mathrm{m}$ metagenomes (Figure 4). In

219 these metagenomes, the most abundant $h g c A B$ genes were attributed to Deltaproteobacteria from

220 the families Desulfobulbaceae and Desulfarculales (Supplementary Table S1). The $3.0 \mu \mathrm{m}$

221 metagenomes from anoxic TF0271 samples (both 140 and $200 \mathrm{~m}$ ) featured higher proportions of

222 genes affiliated with Spirochaetes and Lentisphaerae (Figure 4).

\section{Discussion}

225 Our phylogenetic analysis of the Baltic Sea Reference Metagenome dataset (Alneberg et al., 2018)

226 identified at least 18 different $h g c A B$ gene clusters that belong to several microbial lineages (Figure

227 3, Supplementary File S2 and S3). The majority of $h g c A B$ genes detected were affiliated with

228 Deltaproteobacteria (or Desulfobacterota with GTDB classification) notably in genomes from 
sulfate reducing bacteria (e.g., Compeau and Bartha, 1984, 1985, Gilmour et al., 2013). Some of the

identified Deltaproteobacteria/Desulfobacterota belong to groups of organisms previously known or

231 predicted to perform Hg methylation, such as a species of Desulfobacula (Gionfriddo et al., 2016),

232 members of the Desulfobulbaceae family (Benoit et al., 2001, Colin et al., 2018), and a member of

233 the naphS2 group (Parks et al., 2013). It is noteworthy that none of the $h g c A B$ genes detected in the

234 water of the Baltic Sea were closely related to iron reducing bacteria such as the Geobacteraceae

235 family (Fleming et al., 2006; Kerin et al., 2006; Bravo et al., 2018). However, relatively high Fe(II)

236 concentrations were previously reported in anoxic water from the Baltic Sea (> $25 \mathrm{nM}$; Pohl and

237 Fernandez-Otero, 2012) but with seasonal and inter-annual variability in concentrations. Our

238 finding that none of the $h g c A B$ was closely related to Geobacteraceae suggests that other iron

239 reducing bacteria without the capability to methylate $\mathrm{Hg}$, such as Shewenella sp. (incl S. baltica),

240 are responsible for the formation of Fe(II) in the Baltic sea water column. Indeed, Shewanellaceae

241 are in general one to two orders of magnitude more abundant than Geobacteraceae in the

242 metagenomes compiled in the BalticMicrobeDB (https://barm.scilifelab.se). Our results thus

243 suggest that $\mathrm{Hg}$ methylation is not linked to iron-reduction in the Baltic Sea. Microbial syntrophy,

244 defined as an obligate mutualistic metabolism, is a process known to occur mainly in environments

245 with shortage of favorable electron acceptors, e.g. mostly in anoxic environments (McInerney et al.,

246 2009; Morris et al., 2013). Some syntrophic microbes were recently suggested to be involved in the

247 Hg methylation process (Gilmour et al., 2013; Yu et al., 2018; Hu et al., 2020), but we did not

248 identify $h g c A B$ genes from known syntrophic microorganisms in the Baltic Sea. Instead, we

249 identified $h g c A B$-carrying bacteria in various groups that are still poorly described (McDaniel et al.,

250 2020) including members of Spirochaetes and Lentisphaerae phyla. For instance, among the

251 predominant $h g c A B$-like genes detected in Baltic Sea, the $h g c A B$ genes BARM-01, $-07 \&-09$ were

252 clustered together and found closely related to Spirochaetes (Figure 3). However, it should be

253 noticed that these $h_{c} A B$ genes were also grouped together with various other bacterial groups in

254 the phylogenetic analysis, including MBNT15, Acidobacteria, Actinobacteria and Verrucomicrobia 
255 (Supplementary File S1 for full description), which precludes a more precise identification at

256 present.

258 The 81 metagenomes collected from three sampling efforts (Alneberg et al., 2018) cover substantial

259 variations in water depth, season and location across the Baltic Sea and our study investigates the

260 relationship between putative $\mathrm{Hg}$ methylating populations and these factors. We found higher

261 relative abundance of $h g c A B$ genes in oxygen deficient water (hypoxic and anoxic layers) compared

262 to those observed in normoxic layers also when including an extensive time series (37 time points

263 over the year 2012) at $2 \mathrm{~m}$ depth. This finding is in agreement with the general understanding that

264 methylation of $\mathrm{Hg}$ in aquatic systems is associated with anoxic conditions (Eckley et al., 2005,

265 Malcolm et al., 2010; Compeau and Bartha, 1984, Gilmour et al., 1992, Bravo et al., 2015). Several

266 studies (Goñi-Urriza et al., 2015; Bravo et al., 2016, Christensen et al., 2019) have however

267 demonstrated a poor quantitative relation between $\mathrm{Hg}$ methylation rate and the presence of $h g c A$

268 genes (mRNA and DNA), likely because of additional important factors/processes affecting $\mathrm{Hg}$

269 methylation. Indeed, while Soerensen et al. (2018) found $\mathrm{Hg}$ methylation rate constants below

270 detection limit in both hypoxic and normoxic waters of the Baltic Sea, we find a relatively high

271 abundance of $h g c A B$-like genes in hypoxic water samples at two locations (AT3, $117 \mathrm{~m}$ and S7

$27277 \mathrm{~m}$ ). This finding reveals the potential for $\mathrm{Hg}$ methylation in hypoxic waters.

274 In situ formation of $\mathrm{MeHg}$ in normoxic waters has been proposed to occur in anaerobic microzones

275 formed around organic-rich particulate matter and aggregates, also called marine snow, by several

276 studies (Lehnherr et al., 2001, Monperrus et al., 2007, Cossa et al., 2009, Sunderland et al., 2009,

277 Schartup et al., 2015) and experimentally demonstrated in a few cases (Oritz et al., 2015; Gascon

278 Diez et al., 2016). Our study expands on the role of marine snow for Hg methylation in coastal seas

279 and demonstrates that marine snow is an important habitat for Hg methylators also in anoxic water.

280 Firstly, we found higher relative abundance of $h g c A B$ genes in the metagenome of marine snow 
281 from anoxic $(3.0 \mu \mathrm{m}$ filters $)$ compared to hypoxic $(3.0 \mu \mathrm{m}$ filters) or normoxic (not pre-filter with

$2823.0 \mu \mathrm{m}$ filters) water samples (Figure 4). Considering that the $3.0 \mu \mathrm{m}$ filters represent the particle

283 and aggregated organic matter fraction (that in turn is frequently referred to as marine snow), our

284 results suggest that marine snow becomes a more suitable habitat for $\mathrm{Hg}$ methylators (and thus

285 potentially constitutes an environment with high $\mathrm{Hg}$ methylation rate) when reaching anoxic water.

286 This phenomenon is likely caused by an increased prevalence of anaerobic conditions in the marine

287 snow in anoxic water layers. Secondly, we found a higher proportion of DNA sequences of $h g c A B$

288 genes in $3.0 \mu \mathrm{m}$ metagenomes than in the free-living microbes, represented by the metagenomes

289 obtained from $0.2-3.0 \mu \mathrm{m}$ size fraction, in anoxic waters. This finding could be explained by the

290 marine snow containing high concentrations of organic compounds suitable as metabolic electron

291 donors for many microbial activities occurring in anoxic conditions (Bianchi et al., 2018). It is

292 noticeable that previous studies demonstrated differences between particle-associated and free-

293 living bacterial communities in the Baltic Sea water column but that Spirochaetes and

294 Lentisphaerae, for which $h g c A B$-like genes were found relatively abundant in the $3.0 \mu \mathrm{m}$

295 metagenomes from BARM dataset, were not identified as more predominant in particle-associated

296 bacterial communities (Rieck et al., 2015, BalticMicrobeDB https://barm.scilifelab.se).

298 Our findings advance the understanding of the diversity and distribution of genes involved in $\mathrm{Hg}$

299 methylation as well the $h g c A B$-carrying microbial populations in marine environments. Particularly

300 noteworthy was the finding that most of $h g c A B$-carrying microbes in the Baltic Sea water column

301 were Deltaproteobacteria/Desulfobacterota predominantly found in oxygen-deficient zones (anoxic

302 but also hypoxic zones). In addition, the differences in the relative abundance of $h g c A B$ genes in

303 metagenomes obtained from 0.2 compared to $3.0 \mu \mathrm{m}$ pore size filters suggest marine snow as a

304 niche for $\mathrm{Hg}$ methylating microbial communities and therefore and important potential hotspot for

$305 \mathrm{MeHg}$ formation in both hypoxic and anoxic sea water zones. Finally, our phylogenetic analysis

306 highlights that a substantial part of the $\mathrm{Hg}$ methylators present in the Baltic Sea, and likely in other 
marine environments, are still poorly described and more works are needed to isolate, characterize and describe their genetic diversity.

\section{Conflict of Interest}

The authors declare no conflict of interest

\section{Acknowledgements}

This work was funded by the Swedish research council Formas (grant 2018-01031). The computations were performed on resources provided by SNIC through Uppsala Multidisciplinary Center for Advanced Computational Science (UPPMAX) under Project SNIC 2019/8-322.

\section{References}

Alldredge AL, Silver MW. Characteristics, dynamics and significance of marine snow. Prog Oceanogr 1988; 20: 41-82.

Alneberg J, Sundh J, Bennke C, Beier S, Lundin D, Hugerth LW, et al. Data descriptor: BARM and balticmicrobeDB, a reference metagenome and interface to meta-omic data for the baltic sea. Sci Data 2018; 5: 1-10.

Azam F, Long RA. Sea snow microcosms. Nature 2001; 414: 495-498.

Azam F, Malfatti F. Microbial structuring of marine ecosystems. Nat Rev Microbiol 2007; 5: 782791.

Benoit JM, Gilmour CC, Mason RP. Aspects of bioavailability of mercury for methylation in pure cultures of Desulfobulbus propionicus (1pr3). Appl Environ Microbiol 2001; 67: 51-8.

Bianchi D, Weber TS, Kiko R, Deutsch C. Global niche of marine anaerobic metabolisms expanded by particle microenvironments. Nat Geosci 2018; 11: 1-6.

Blum JD, Popp BN, Drazen JC, Anela Choy C, Johnson MW. Methylmercury production below the mixed layer in the North Pacific Ocean. Nat Geosci 2013; 6: 879-884.

Bravo AG, Cosio C. Biotic formation of methylmercury: A bio-physico-chemical conundrum. Limnol Oceanogr 2019; 1-18.

Bravo A, Peura S, Buck M, Ahmed O, Mateos-Rivera A, Ortega S, et al. Methanogens and IronReducing Bacteria $\square$ : the Overlooked Members of Mercury-Methylating Microbial Communities in. Appl Environ Microbiol 2018; 84: 1-16.

Bravo AG, Loizeau JL, Dranguet P, Makri S, Björn E, Ungureanu VG, et al. Persistent Hg contamination and occurrence of Hg-methylating transcript (hgcA) downstream of a chlor-alkali plant in the Olt River (Romania). Environ Sci Pollut Res 2016; 23: 10529-10541.

Bravo AG, Bouchet S, Guédron S, Amouroux D, Dominik J, Zopfi J. High methylmercury production under ferruginous conditions in sediments impacted by sewage treatment plant discharges. Water Res 2015; 80: 245-255.

Bowman KL, Collins RE, Agather AM, Lamborg CH, Hammerschmidt CR, Kaul D, et al. Distribution of mercury $\square$ cycling genes in the Arctic and equatorial Pacific Oceans and their relationship to mercury speciation. Limnol Oceanogr 2019; 1-11.

Breitburg D, Levin LA, Oschlies A, Grégoire M, Chavez FP, Conley DJ, et al. Declining oxygen in the global ocean and coastal waters. Science 2018; 359. 
349 Carstensen J, Andersen JH, Gustafsson BG, Conley DJ. Deoxygenation of the Baltic Sea during the

350 last century. Proc Natl Acad Sci U S A 2014; 111: 5628-33.

351 Christensen GA, Gionfriddo CM, King AJ, Moberly JG, Miller CL, Somenahally AC, et al.

352 Determining the Reliability of Measuring Mercury Cycling Gene Abundance with Correlations with

353 Mercury and Methylmercury Concentrations. Environ Sci Technol 2019; 53: 8649-8663.

354 Colin Y, Gury J, Monperrus M, Gentes S, Ayala Borda P, Goni-Urriza M, et al. Biosensor for

355 screening bacterial mercury methylation: example within the Desulfobulbaceae. Res Microbiol

356 2018; 169: 44-51.

357 Compeau GC, Bartha R. Principal Methylators. Microbiology 1985; 50: 498-502.

358 Compeau G, Bartha R. Methylation and demethylation of mercury under controlled redox, $\mathrm{pH}$, and

359 salinity conditions. Appl Environ Microbiol 1984; 48: 1203-1207.

360 Conley DJ, Carstensen J, Aigars J, Axe P, Bonsdorff E, Eremina T, et al. Hypoxia Is Increasing in 361 the Coastal Zone of the Baltic Sea. Environ Sci Technol 2011; 45: 6777-6783.

362 Cossa D, Averty B, Pirrone N. The origin of methylmercury in open mediterranean waters. Limnol 363 Oceanogr 2009; 54: 837-844.

364 Eckley CS, Watras CJ, Hintelmann H, Morrison K, Kent AD, Regnell O. Mercury methylation in 365 the hypolimnetic waters of lakes with and without connection to wetlands in northern Wisconsin.

366 Can J Fish Aquat Sci 2005; 62: 400-411.

367 Finn RD, Clements J, Eddy SR. HMMER web server: interactive sequence similarity searching.

368 Nucleic Acids Res 2011; 39: W29-W37.

369 Fleming EJ, Mack EE, Green PG, Nelson DC. Mercury methylation from unexpected sources:

370 molybdate-inhibited freshwater sediments and an iron-reducing bacterium. Appl Environ Microbiol

371 2006; 72: 457-64.

372 Gascón Díez E, Loizeau JL, Cosio C, Bouchet S, Adatte T, Amouroux D, et al. Role of Settling

373 Particles on Mercury Methylation in the Oxic Water Column of Freshwater Systems. Environ Sci

374 Technol 2016; 50: 11672-11679.

375 Gilmour CC, Henry EA, Ralph M. Sulfate Stimulation of Mercury Methylation in Freshwater

376 Sediments. Environ Sci Technol 1992; 26: 2281-2287.

377 Gilmour CC, Podar M, Bullock AL, Graham AM, Brown SD, Somenahally AC, et al. Mercury 378 methylation by novel microorganisms from new environments. Environ Sci Technol 2013; 47: 379 11810-11820.

380 Gionfriddo CM, Tate MT, Wick RR, Schultz MB, Zemla A, Thelen MP, et al. Microbial mercury 381 methylation in Antarctic sea ice. Nat Microbiol 2016; 1: 1-12.

382 Goñi-Urriza M, Corsellis Y, Lanceleur L, Tessier E, Gury J, Monperrus M, et al. Relationships 383 between bacterial energetic metabolism, mercury methylation potential, and $\mathrm{hgcA} / \mathrm{hgcB}$ gene 384 expression in Desulfovibrio dechloroacetivorans BerOc1. Environ Sci Pollut Res 2015; 22: 13764 38513771.

386 Haro-Moreno JM, López-Pérez M, de la Torre JR, Picazo A, Camacho A, Rodriguez-Valera F. Fine 387 metagenomic profile of the Mediterranean stratified and mixed water columns revealed by assembly 388 and recruitment. Microbiome 2018; 6: 1-19.

389 Hu H, Wang B, Bravo AG, Björn E, Skyllberg U, Amouroux D, et al. Shifts in mercury methylation 390 across a peatland chronosequence: From sulfate reduction to methanogenesis and syntrophy. $J$ 391 Hazard Mater 2020; 387: 121967.

392 Kerin EJ, Gilmour CC, Roden E, Suzuki MT, Coates JD, Mason RP. Mercury methylation by 393 dissimilatory iron-reducing bacteria. Appl Environ Microbiol 2006; 72: 7919-7921. 
394 Kumar S, Stecher G, Li M, Knyaz C, Tamura K. MEGA X: Molecular Evolutionary Genetics

395 Analysis across Computing Platforms. Mol Biol Evol 2018; 35: 1547-1549.

396 Kuss J, Krüger S, Ruickoldt J, Wlost K-P. High-resolution measurements of elemental mercury in

397 surface water for an improved quantitative understanding of the Baltic Sea as a source of

398 atmospheric mercury. Atmos Chem Phys 2018; 18: 4361-4376.

399 Lehnherr I, St. Louis VL, Hintelmann H, Kirk JL. Methylation of inorganic mercury in polar marine 400 waters. Nat Geosci 2011; 4: 298-302.

401 Letunic I, Bork P. Interactive Tree Of Life (iTOL) v4: recent updates and new developments. 402 Nucleic Acids Res 2019; 47: W256-W259.

403 Li D, Liu C-M, Luo R, Sadakane K, Lam T-W. MEGAHIT: an ultra-fast single-node solution for 404 large and complex metagenomics assembly via succinct de Bruijn graph. Bioinformatics 2015; 31: 405 1674-1676.

406 Malcolm EG, Schaefer JK, Ekstrom EB, Tuit CB, Jayakumar A, Park H, et al. Mercury methylation 407 in oxygen deficient zones of the oceans: No evidence for the predominance of anaerobes. Mar 408 Chem 2010; 122: 11-19.

409 Mason R, Choi AL, Fitzgerald WF, Hammerschmidt CR, Lamborg CH, Soerensen AL. Mercury 410 biogeochemical cycling in the ocean and policy implications. Environ Res 2012; 119: 101-117.

411 McInerney MJ, Sieber JR, Gunsalus RP. Syntrophy in anaerobic global carbon cycles. Curr Opin 412 Biotechnol 2009; 20: 623-632.

413 McDaniel EA, Peterson B, Stevens SLR, Tran PQ, Anantharaman K, McMahon KD. Expanded 414 Phylogenetic Diversity and Metabolic Flexibility of Microbial Mercury Methylation. bioRxiv 2020; 4152020.01 .16 .909358$.

416 Mehrshad M, Amoozegar MA, Ghai R, Shahzadeh Fazeli SA, Rodriguez-Valera F. Genome 417 reconstruction from metagenomic data sets reveals novel microbes in the brackish waters of the 418 Caspian Sea. Appl Environ Microbiol 2016; 82: 1599-1612.

419 Monperrus M, Tessier E, Amouroux D, Leynaert A, Huonnic P, Donard OFX. Mercury 420 methylation, demethylation and reduction rates in coastal and marine surface waters of the 421 Mediterranean Sea. Mar Chem 2007; 107: 49-63.

422 Morris BEL, Henneberger R, Huber H, Moissl-Eichinger C. Microbial syntrophy: Interaction for 423 the common good. FEMS Microbiol Rev 2013; 37: 384-406.

424 Nowinski B, Motard-Côté J, Landa M, Preston CM, Scholin CA, Birch JM, et al. Microdiversity 425 and temporal dynamics of marine bacterial dimethylsulfoniopropionate genes. Environ Microbiol 426 2019; 21: 1687-1701.

427 Ortiz VL, Mason RP, Evan Ward J. An examination of the factors influencing mercury and 428 methylmercury particulate distributions, methylation and demethylation rates in laboratory429 generated marine snow. Mar Chem 2015; 177: 753-762.

430 Parks JM, Johs A, Podar M, Bridou R, Hurt RA, Smith SD, et al. The genetic basis for bacterial 431 mercury methylation. Science 2013; 339: 1332-1335.

432 Podar M, Gilmour CC, Brandt CC, Soren A, Brown SD, Crable BR, et al. Global prevalence and 433 distribution of genes and microorganisms involved in mercury methylation. Sci Adv 2015; 1: 1-13.

434 Pohl C, Fernández-Otero E. Iron distribution and speciation in oxic and anoxic waters of the Baltic 435 Sea. Mar Chem 2012; 145-147: 1-15.

436 Price M, Dehal P, Arkin A. FastTree: computing large minimum evolution trees with profiles 437 instead of a distance matrix. Mol Biol Evol 2009; 26: 1641-1650. 
438 Rieck A, Herlemann DPR, Jürgens K, Grossart H-P. Particle-Associated Differ from Free-Living 439 Bacteria in Surface Waters of the Baltic Sea. Front Microbiol 2015; 6: 1297.

440 Schartup AT, Balcom PH, Soerensen AL, Gosnell KJ, Calder RSD, Mason RP, et al. Freshwater 441 discharges drive high levels of methylmercury in Arctic marine biota. Proc Natl Acad Sci U S A 442 2015; 112: 11789-11794.

443 Soerensen AL, Schartup AT, Skrobonja A, Bouchet S, Amouroux D, Liem-Nguyen V, et al. 444 Deciphering the Role of Water Column Redoxclines on Methylmercury Cycling Using Speciation 445 Modeling and Observations From the Baltic Sea. Global Biogeochem Cycles 2018; 32: 1498-1513.

446 Soerensen AL, Schartup AT, Gustafsson E, Gustafsson BG, Undeman E, Björn E. Eutrophication 447 Increases Phytoplankton Methylmercury Concentrations in a Coastal Sea - A Baltic Sea Case Study. 448 Environ Sci Technol 2016; 50: 11787-11796.

449 Sunderland EM, Krabbenhoft DP, Moreau JW, Strode SA, Landing WM. Mercury sources, 450 distribution, and bioavailability in the North Pacific Ocean: Insights from data and models. Global 451 Biogeochem Cycles 2009; 23: n/a-n/a.

452 Villar E, Cabrol L, Heimbürger $\square$ Boavida L. Widespread microbial mercury methylation genes in 453 the global ocean. Environ Microbiol Rep 2020; 1758-2229.12829.

454 Yu RQ, Reinfelder JR, Hines ME, Barkay T. Syntrophic pathways for microbial mercury 455 methylation. ISME J 2018; 12: 1826-1835.

\section{Figure legends}

458 Figure 1. Location of study sites in the Baltic Sea

459 Figure 2. Alignment of conserved regions for protein sequences of the nine hgcAB-like gene 460 clusters, (BARM-01 to 09) 13 hgcA-like genes (BARM-10 to 22) three hgcB-like genes (BARM-23 461 to 25) detected in the BARM dataset. The corresponding hgcAB Protein sequences from 462 Desulfovibrio desulfuricans ND132 and Geobacter sulfurreducens PCA were added in the 463 alignment as references.

464 Figure 3. Phylogenetic tree of hgcAB gene clusters with collapsed clades. Collapsed clades are 465 discriminated with colors based on their taxonomy. Gene clusters detected in the Baltic Sea water 466 column (BARM) are displayed in bold.

467 Figure 4. Relative abundance of hgcA- and hgcB-like genes in samples from the dataset 468 "Redoxcline 2014" and "Transect 2014". The dataset "LMO 2012" is not included because only 469 few genes were detected and at low abundances (data shown in Supplementary Table S1). The 470 sampling time is written using the YYMMDD format. The sampling depth $(\mathrm{m})$ is color coded based 471 on its respective gradient (darker shade of gray with increasing depth). The water redox zone is 472 color coded based on the $\mathrm{O} 2$ categories defined in the text (light blue for normoxic, beige for 473 hypoxic and brown for anoxic conditions). The abbreviations "Filtr." and "Pre-filtr." indicate the 474 pore size of the filters used to obtain each metagenome and if pre-filtration were done prior to 475 filtration, respectively.

477 Tables

478 Table 1. Description of the number of metagenomes obtained with their respective sampling and 479 filtration strategies for each of the three datasets.

\begin{tabular}{cccc}
\hline $\begin{array}{c}\text { Sample set } \\
\text { name }\end{array}$ & $\begin{array}{c}\text { Number of } \\
\text { samples }\end{array}$ & Sampling & Filtration \\
\hline
\end{tabular}




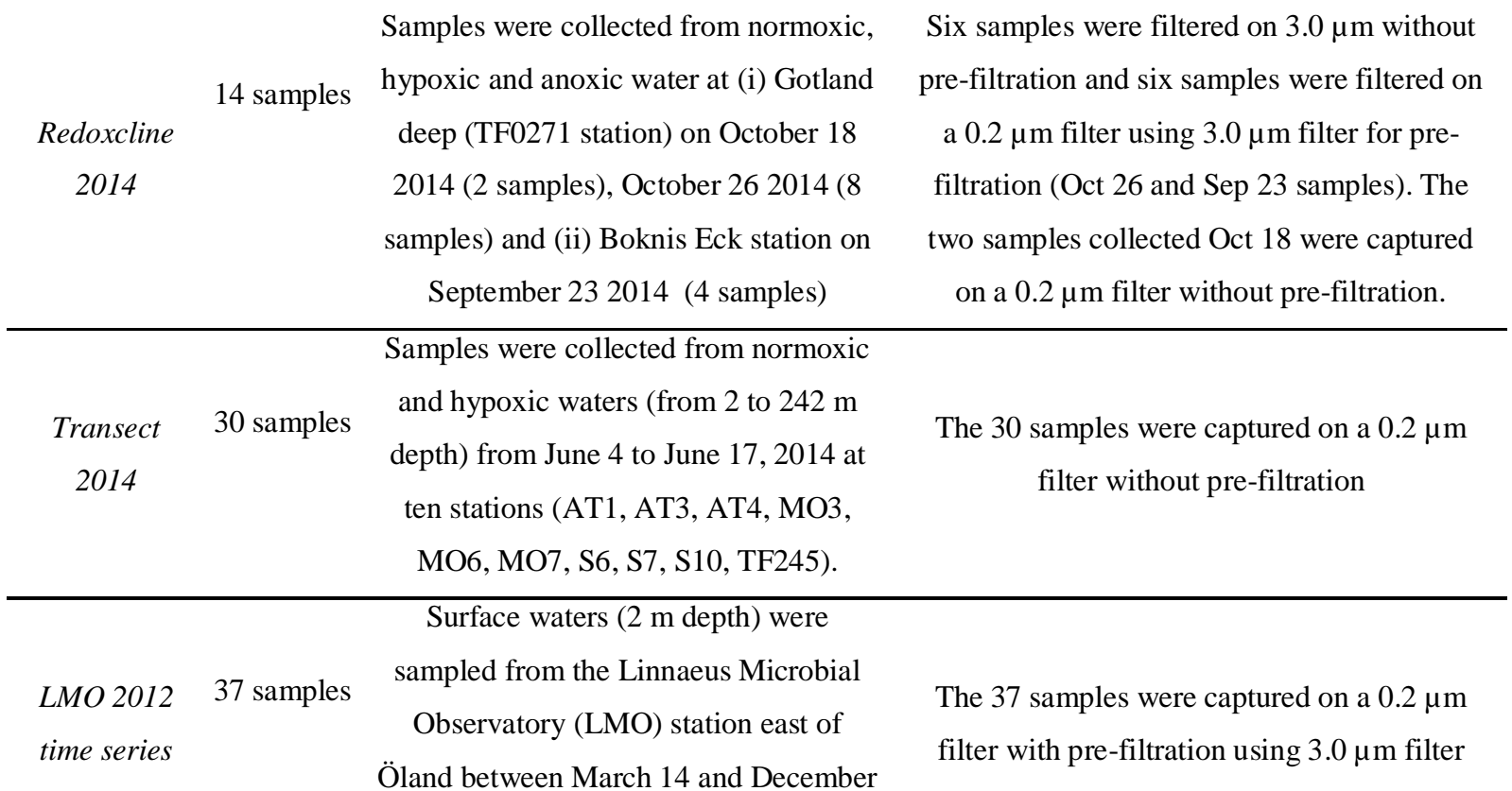

$20,2012$.

Table 2: Proportion (units in $1 \times 10^{-3}$; normalized to total DNA sequences count of each 482 metagenome) of $h g c A B$-like genes in the 81 metagenomes. The values obtained from the 483 metagenomes collected in the three type of water defined in this study (normoxic, hypoxic and 484 anoxic water) are displayed in this table.

\begin{tabular}{lcccc}
\hline Samples & mean & $\begin{array}{c}\text { standard } \\
\text { deviation }\end{array}$ & min & max \\
\hline normoxic water $(\mathrm{n}=65)$ & $<0.1$ & $<0.1$ & 0.0 & 0.2 \\
hypoxic water $(\mathrm{n}=9)$ & 1.0 & 2.2 & $<0.1$ & 6.7 \\
anoxic water $(\mathrm{n}=7)$ & 2.1 & 2.5 & $<0.1$ & 6.5 \\
all water $(\mathrm{n}=81)$ & 0.3 & 1.2 & 0.0 & 6.7 \\
\hline
\end{tabular}

\section{Captions of supplementary material}

487 Supplementary Table S1. Proportion of $h g c A B$ genes (out of the total number of reads of each 488 metagenome) in each metagenome from the three datasets used in the present study. The protein 489 sequences, taxonomic identifications associated to each gene are displayed. The environmental 490 conditions associated to the water samples for each metagenome are displayed.

491 Supplementary Text S1. $H g c A B$ protein sequences of HMM profiles modified from Podar et al. 492 (2015) 
493 Supplementary Text S2. Protein sequences of $h g c A B$ gene clusters identified in 650 bacterial and

494 archaeal genomes (McDaniel et al., 2020).

495 Supplementary Text S3. Protein sequences of $h g c A B$-like genes detected in BARM dataset

496 Supplementary File S1. Extended phylogenetic tree of $h g c A B$ genes performed from the protein

497 sequences of $650 \mathrm{hgcAB}$ gene clusters (McDaniel et al., 2020) and BARM hgcAB genes (in newick

498 format).

499 Supplementary File S2. Extended phylogenetic tree of $h g c A$ genes performed from the protein

500 sequences of $650 \mathrm{hgcA}$ genes (McDaniel et al., 2020) and BARM hgcA genes (in newick format).

501 Supplementary File S3. Extended phylogenetic tree of $h g c B$ genes performed from the protein 502 sequences of $650 \mathrm{hgcB}$ genes (McDaniel et al., 2020) and BARM $h g c B$ genes (in newick format). 


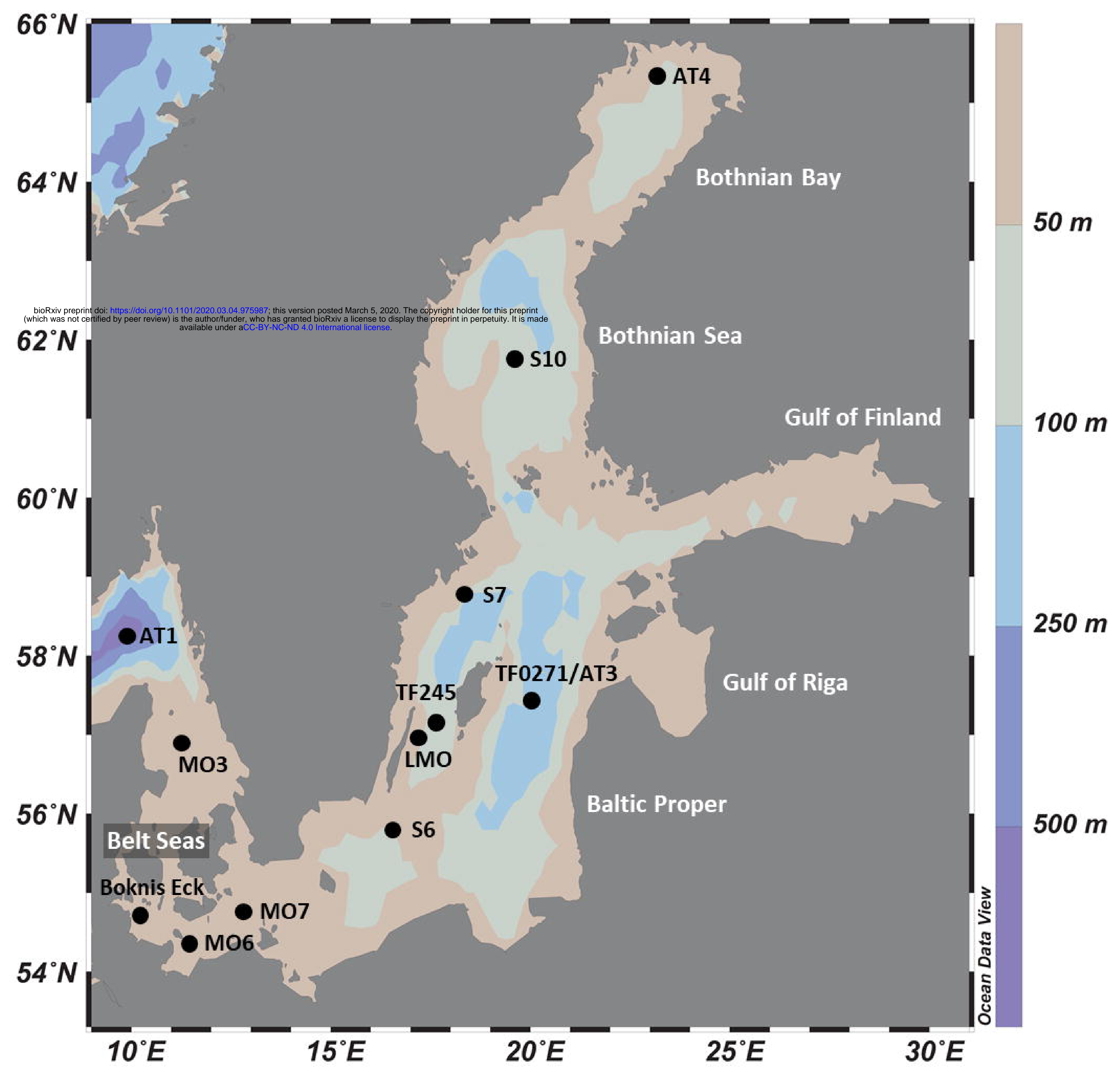




\section{protein-coding sequence}

Desulfovibrio desulfuricans ND132 R W E L A G R D I W L L V L E T H G I|N VWCAAG K G T F G T D E IV Geobacter sulfurreducens PCA R E R L T S I D AWL L V VD TR G I N VWC A A G K G L F TAS EVA BARM-01_hgcAB VR GVAGR PVRLLLVDTDG।NVWCAS GKGR F S E L IV BARM-02_hgcAB .............. L T D G VN VWC A A G K G TFG TE E L I BARM-03_hgcAB RRQLVG I DAWVLVLDTGG I N VWCAAGK GTFGTDELV BARM-04_hgcAB RKQLDD I N AW I L VLDTKG IN VWCAAGKGTFS TLELV BARM-05_hgcAB RRELGGRDLWILVLDTANVN VWCAAGKGTFGTAELV BARM-06_hgcAB RS S L P G I D AWLLVLDTKG I N VWCAAGK GTFGTAELV BARM-07_hgcAB ..... ER N VRLLVVDTDG IN VWC AAGKGQFSETVIF BARM-08_hgcAB ........................ G G G T F S TR E LV BARM-09_hgcAB VRGAGGRPFRLLVVDSDG INVWCASGKGRFSAGL I L BARM-10_hgcA RESLSGRNAWILVLDTDG IN VWCAAGKGTFGTEELV BARM-11_hgcA ............. MVD TR G I N VWCAAG K K T F TAE E VA BARM-12_hgcA RRTLAGVDAWILVLDTKG I NVWCAAGKGTFGTSEL I BARM-13 hgcA R S S L R G S GY I L VLDTK GVN VWC A A G K K TF G T DEL L BARM-14_hgcA RSELGGRDVWILVLDTNG। NVWCAAGK GTFGTQELL BARM-15_hgcA RKELTNLDVWILVVDTR G INVWCAAGKGTFSTEEVT BARM-16_hgcA RSQLSGRDGWILVIETFG IN NWCAAGK GTFGTDE IV BARM-17_hgcA RKELTNLDVWILVVDTRG INVWCAAGKGTFSTEEVA BARM-18 hgcA R S QLGGRDCWILVLDTKG INVWCAAGKGTFGTFELV BARM-19_hgcA RCALSDQNAWILVLDTKG। N VWCAAGKGTFGTNELV BARM-20_hgcA R TALSGRDGWILVIDTR G IN VWCAAGKGTFGTAE I V BARM-21 hgcA LRELGATPVRLLVVDTDG।NVWCAAGKGVFSNEA IN BARM-22_hgcA RSALYGRTGWILVLDTAGINVWCAAGKGSFGTEELV BARM-23_hgcB BARM-24 hgcB BARM-25_hgcB portion of $h g c B$

\section{protein-coding sequence}

VEVCPHQVFRLEGSKAEVARD-D C MECGAC A VNCPASA IRVDAGVGCAS VDVCPHRILAVRERKTTILDFDACMECGACARNCPVEA I TVTPGTGCAA VLVCPHGVLA IEARKAVPHRH - RCIECGACQLNCAPGAMHVTKGTGCLV I TVCPHLVFSMNNGNAK I DNRDACMECGACARNCPSGALFVKAGVGCAA VSVCPHAVFLLGNRKAR IVDRDACMECGACGLNCPEDAIQGRSGAGCAA T QVCPQAVFEMRHNKTH I VDFNACMECGACVNNCPSEAISVSPGVG ... PEVCPHAVFLVKDRKAKIVDRDACMECGACVRNCPVGALSVAAGAGCVA T TVCPHAVF I I ENKKAVLANFNSCMECGACQRNCAFNALEVRSGVGCAG AK I C PHRV IELQDRQAFLIAEER C IECGACQLNCTEGA ISVTKGTGCLL TEVCPHTVFEMRENKAR I VDFNACMECGACVNNCPSQAISVNPGVG... ALVCPHGVLTIENRKATLSHRER C I ECGACQLNCSPGAMHVTKGTGCLV

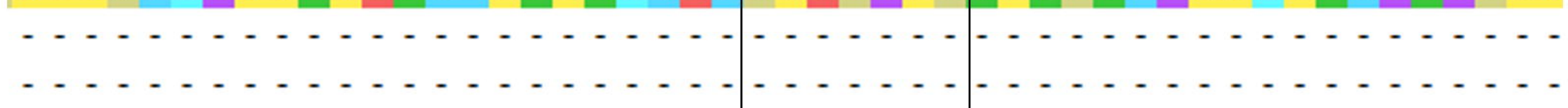

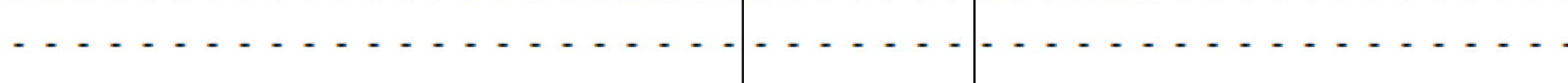

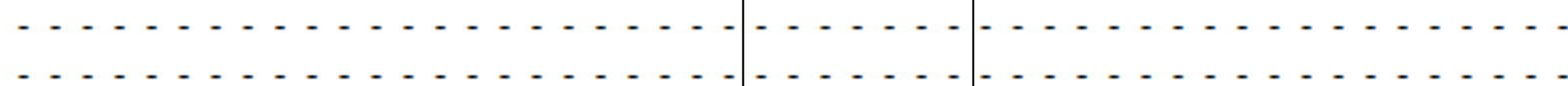

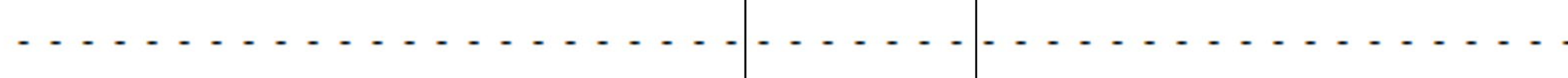

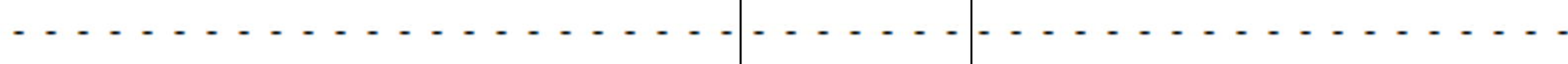
-

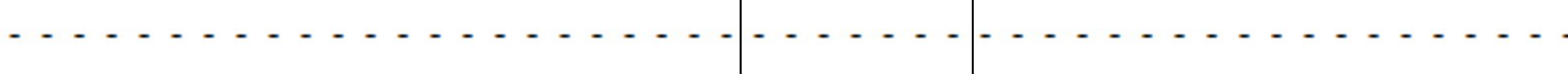

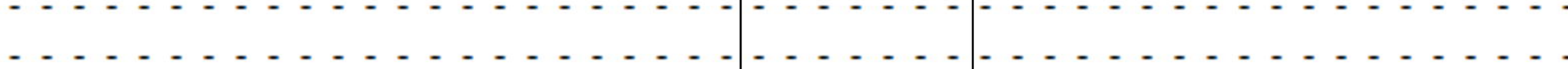
MTVCPHAVFVLREKKAD I TDRDACMECGACAGNCPADAIAVEAGVGCAT $L I V C P H A V F A P G E H A V V L A N P Q D C M E C G A C Q V N C P V D A \mid I V D S G V G C A A$ AKVCPHGVLRMVDKRAVLAAEER/C IECGAC|QLNCHDEAIFVTKGTGCLF 
BARM-05 hgcAB

Lentisphaerae Lenti-02

Verrucomicrobia Akkermansiaceae
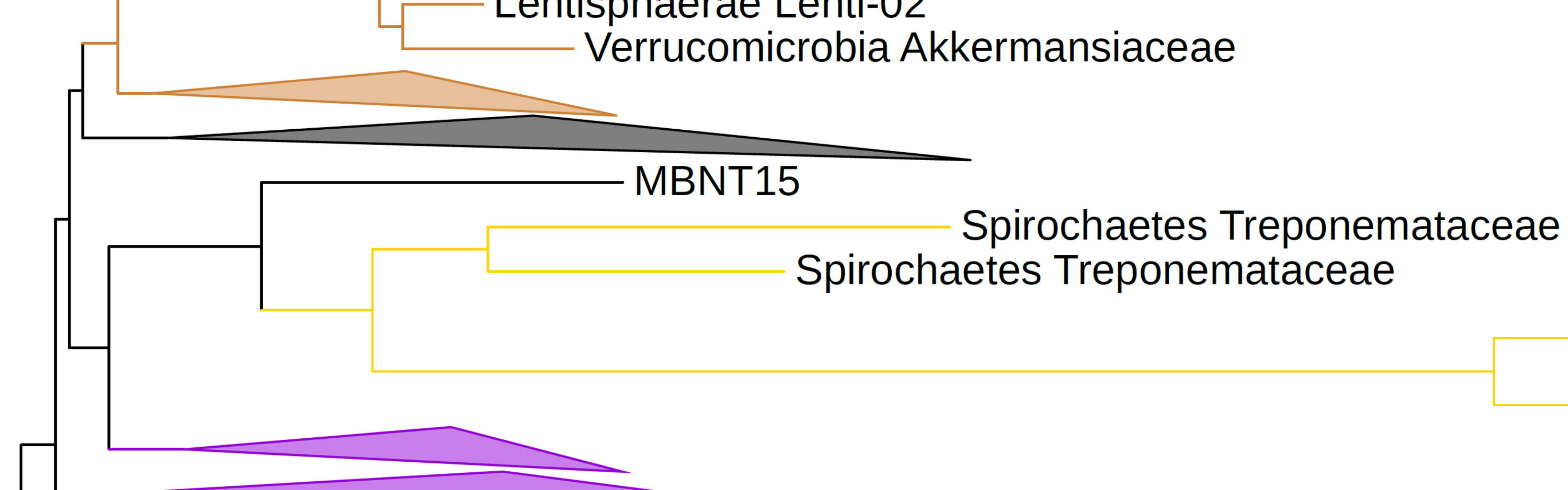

BARM-06 hgcAB

Deltaproteobacteria Desulfarculaceae Dethiosulfatarculus
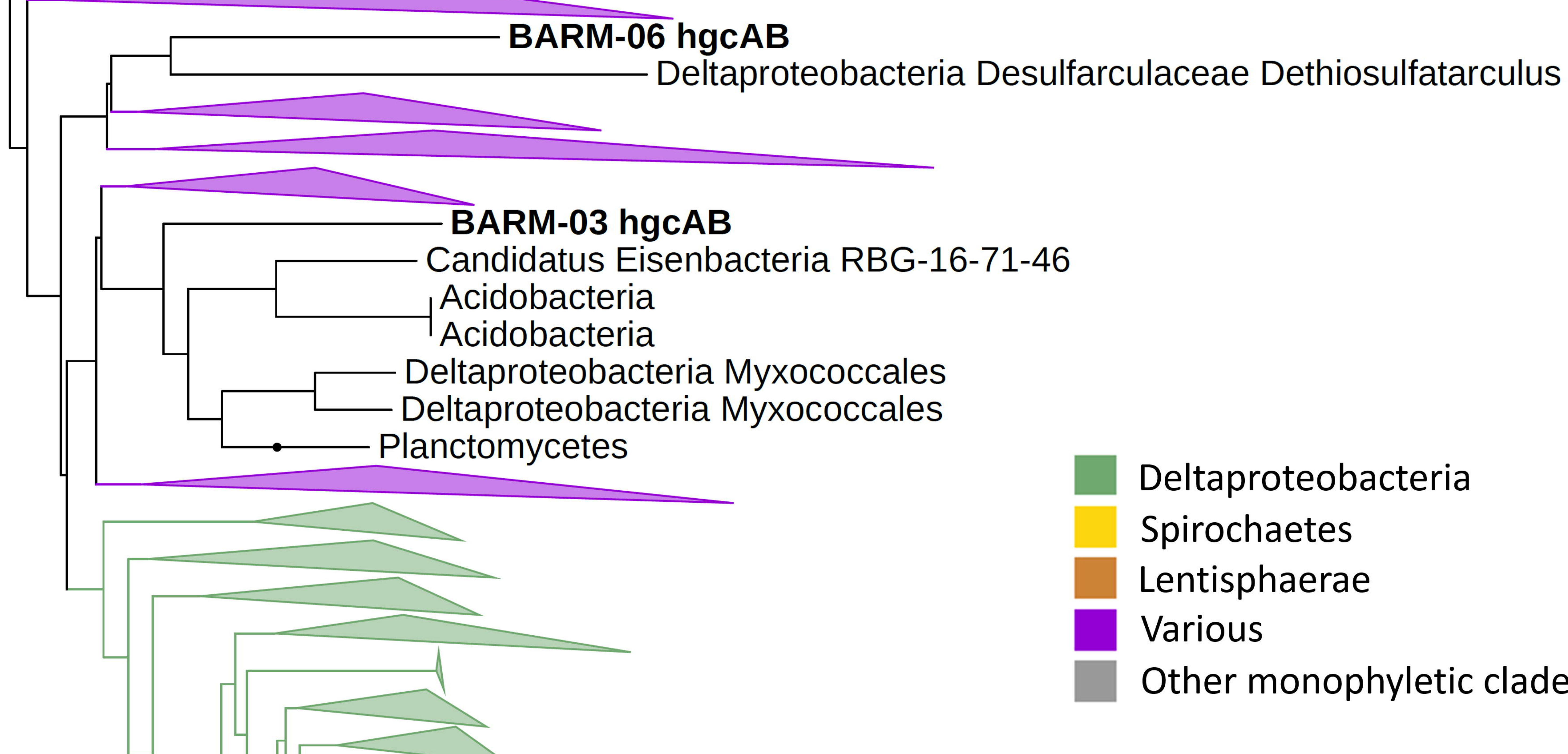

Deltaproteobacteria
Spirochaetes
Lentisphaerae
Various
Other monophyletic clades
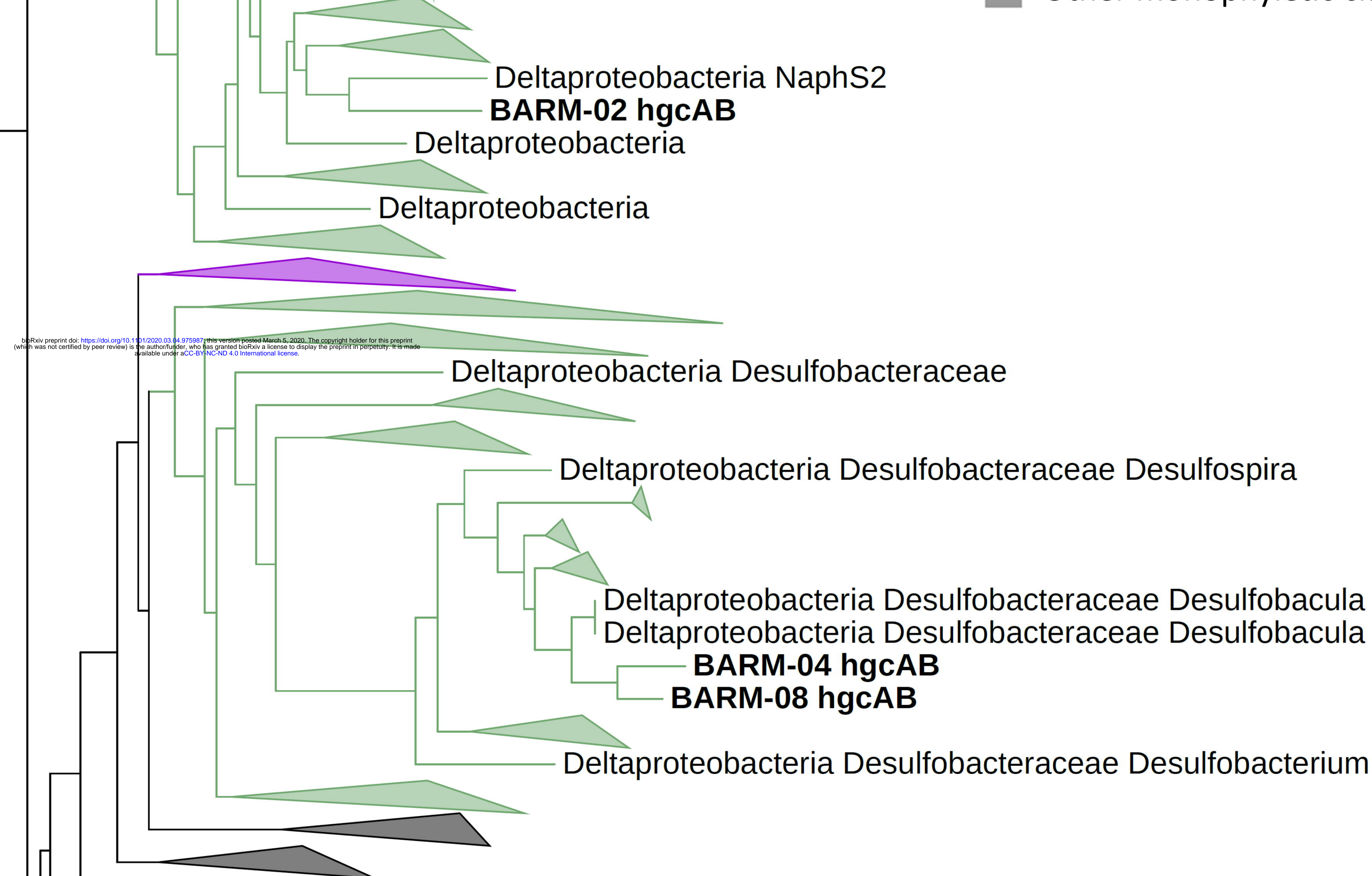

Firmicutes Clostridia

Lentisphaerae Kiritimatiellae 
Time Salinity Water depth

Station (yymmdd) (psu) (m)

Redox zone $\begin{array}{llllllll}0 & 1 & 2 & 3 & 4 & 5 & 6 & 7\end{array}$

Filtr. Pre-filtr.

\begin{tabular}{|c|c|c|c|c|c|c|c|}
\hline AT4 & 140612 & 2.4 & 2 & Normoxic & & 0.2 & - \\
\hline AT4 & 140612 & 3 & 42 & Normoxic & & 0.2 & - \\
\hline AT4 & 140612 & 3.1 & 79 & Normoxic & & 0.2 & - \\
\hline S10 & 140612 & 5.5 & 2 & Normoxic & & 0.2 & - \\
\hline S10 & 140612 & 5.5 & 34 & Normoxic & & 0.2 & - \\
\hline $\mathrm{S} 10$ & 140612 & 5.6 & 56 & Normoxic & & 0.2 & - \\
\hline S7 & 140616 & 6.7 & 2 & Normoxic & & 0.2 & - \\
\hline S7 & 140616 & 7.2 & 61 & Normoxic & & 0.2 & - \\
\hline S7 & 140616 & 9.2 & 77 & Hypoxic & & 0.2 & - \\
\hline AT3 & 140609 & 6.7 & 1 & Normoxic & & 0.2 & - \\
\hline AT3 & 140609 & 7.2 & 65 & Normoxic & & 0.2 & - \\
\hline AT3 & 140609 & 10.9 & 117 & Hypoxic & & 0.2 & - \\
\hline TF0271 & 141018 & 10.5 & 100 & Hypoxic & & 0.2 & - \\
\hline TF0271 & 141018 & 11.7 & 139 & Anoxic & & 0.2 & - \\
\hline TF0271 & 141026 & 11 & 110 & Hypoxic & & 3 & - \\
\hline TF0271 & 141026 & 11 & 110 & Hypoxic & & 0.2 & 3 \\
\hline TF0271 & 141026 & 11.3 & 120 & Hypoxic & & 3 & - \\
\hline TF0271 & 141026 & 11.3 & 120 & Hypoxic & & 0.2 & 3 \\
\hline TF0271 & 141026 & 11.8 & 140 & Anoxic & & 3 & - \\
\hline TF0271 & 141026 & 11.8 & 140 & Anoxic & & 0.2 & 3 \\
\hline TF0271 & 141026 & 12.1 & 200 & Anoxic & & 3 & - \\
\hline TF0271 & 141026 & 12.1 & 200 & Anoxic & & 0.2 & 3 \\
\hline TF245 & 140617 & 7.1 & 3 & Normoxic & & 0.2 & - \\
\hline TF245 & 140617 & 7.3 & 56 & Normoxic & & 0.2 & - \\
\hline TF245 & 140617 & 8.9 & 86 & Hypoxic & & 0.2 & - \\
\hline S6 & 140608 & 7.6 & 3 & Normoxic & \multirow{9}{*}{$\begin{array}{l}\text { Deltaproteobacteria } \\
\text { Spirochaetes } \\
\text { Lentisphaerae } \\
\text { Euryarchaea-Chloroflexi } \\
\text { Firmicutes } \\
\text { Unidentified }\end{array}$} & 0.2 & - \\
\hline S6 & 140608 & 7.7 & 30 & Normoxic & & 0.2 & - \\
\hline S6 & 140608 & 15.7 & 67 & Hypoxic & & 0.2 & - \\
\hline MO7 & 140604 & 8.3 & 3 & Normoxic & & 0.2 & - \\
\hline MO7 & 140604 & 15 & 13 & Normoxic & & 0.2 & - \\
\hline MO7 & 140604 & 16.4 & 19 & Normoxic & & 0.2 & - \\
\hline Mo6 & 140607 & 10.3 & 2 & Normoxic & & 0.2 & - \\
\hline Mo6 & 140607 & 14.7 & 16 & Normoxic & & 0.2 & - \\
\hline $\mathrm{MO} \mathrm{CH}^{-}$ & 140607 & 20.3 & 23 & Normoxic & & 0.2 & - \\
\hline Boknis_Eck & 140923 & 16.3 & 10 & Normoxic & & 3 & - \\
\hline Boknis_Eck & 140923 & 16.3 & 10 & Normoxic & & 0.2 & 3 \\
\hline Boknis_Eck & 140923 & 25.1 & 25 & Anoxic & & 3 & - \\
\hline Boknis_Eck & 140923 & 25.1 & 25 & Anoxic & & 0.2 & 3 \\
\hline MO3 & 140606 & 14.5 & 3 & Normoxic & & 0.2 & - \\
\hline MO3 & 140606 & 17.6 & 11 & Normoxic & & 0.2 & - \\
\hline MO3 & 140606 & 31.9 & 21 & Normoxic & & 0.2 & - \\
\hline AT1 & 140605 & 28.1 & 2 & Normoxic & & 0.2 & - \\
\hline AT1 & 140605 & 34.9 & 80 & Normoxic & & 0.2 & - \\
\hline AT1 & 140605 & 35.1 & 242 & Normoxic & & 0.2 & - \\
\hline
\end{tabular}

